\title{
Photoperiodic flower induction in Ipomoea nil is accompanied by decreasing content of gibberellins
}

\author{
Katarzyna Marciniak ${ }^{1,2} \cdot$ Agata Kućko $^{1} \cdot$ Emilia Wilmowicz $^{1,2} \cdot$ Michał Świdziński $^{3}$. \\ Jacek Kęsy ${ }^{1,2} \cdot$ Jan Kopcewicz ${ }^{1}$
}

Received: 28 April 2017 / Accepted: 1 November 2017 / Published online: 8 November 2017

(C) The Author(s) 2017. This article is an open access publication

\begin{abstract}
The involvement of gibberellins (GAs) in the control of flower induction in the short-day plant Ipomoea nil has been investigated. To clarify the molecular basis of this process, we identified the full-length cDNAs of the InGA20ox 3 and InGA2oxl genes, which encode enzymes responsible for GA biosynthesis and catabolism, respectively. We studied the expression patterns of both genes and determined the tissue and cellular immunolocalisation of gibberellic acid $\left(\mathrm{GA}_{3}\right)$ in the cotyledons of 5-day-old seedlings growing under inductive and non-inductive photoperiodic conditions. In the second half of the inductive night, which is crucial for flower induction in I. nil, InGA20ox 3 expression decreased, whereas InGA2oxl mRNA accumulated, which indicates that photoperiod regulates the activity of both genes. Furthermore, these changes are correlated with $\mathrm{GA}_{3}$ level. Thus, our results support the thesis that the proper balance between the expression of the InGA20ox 3 and InGA2oxl genes and low $\mathrm{GA}_{3}$ content correlate with photoperiodic flower induction in I. nil.
\end{abstract}

Electronic supplementary material The online version of this article (https://doi.org/10.1007/s10725-017-0344-6) contains supplementary material, which is available to authorized users.

Katarzyna Marciniak

marciniak@umk.pl

1 Chair of Plant Physiology and Biotechnology, Nicolaus Copernicus University, 1 Lwowska Street, 87-100 Toruń, Poland

2 Centre for Modern Interdisciplinary Technologies, Nicolaus Copernicus University, 4 Wileńska Street, 87-100 Toruń, Poland

3 Department of Cell Biology, Nicolaus Copernicus University, 1 Lwowska Street, 87-100 Toruń, Poland
Keywords Gibberellins · Flowering · Photoperiod · Short-day plant $\cdot$ Ipomoea nil

\section{Introduction}

The reproductive success of plants is maintained by the precise control of the flowering time with the participation of several factors including photoperiod and gibberellins (GAs). The key enzymes of GA metabolism are gibberellin 20-oxidases (GA20oxs) and gibberellin 2-oxidases (GA2oxs), which belong to the 2-oxoglutarate-dependent dioxygenases (2ODDs) superfamily. While GA20oxs activate GAs by oxidizing carbon 20, GA2oxs are responsible for their deactivation ( $2 \beta$-hydroxylation) (Olszewski et al. 2002). The role of GAs in the regulation of flowering is species-specific and depends primarily on the photoperiodic sensitivity of the plant. In short-day plants (SDPs), e.g., Oryza sativa or Fragaria ananassa, which require a longer period of darkness than light to transition from the vegetative to generative stage, GAs are generally inhibitors or have no influence on flowering. On the other hand, long-day plants (LDPs), e.g., Arabidopsis thaliana, Lolium temulentum or Spinacia oleracea are induced to flower by short nights, and GAs mostly stimulate this process (Mutasa-Gottgens and Hedden 2009; Zeevaart 1983). However, in the case of the facultative LDP A. thaliana, the GA-dependent pathway has a relatively minor influence on flowering time under inductive conditions, whereas in the absence of the photoperiodic stimulus, the transition from the vegetative to generative phase is induced mainly by GAs (Mutasa-Gottgens and Hedden 2009). Hisamatsu et al. (2005) demonstrated that loss of AtGA20ox2 delays flowering in inductive longday (LD) conditions, but a stronger effect was observed 
in non-inductive short-day (SD) conditions (Hisamatsu et al. 2005). In turn, AtGA20oxl, which shows a circadian expression pattern in the leaf blade and petiole, has much less influence on flowering (Rieu et al. 2008). In $S$. oleracea the level of SoGA20oxl transcript and the encoded protein increased in leaves and shoot apices when plants were transferred from SD to LD conditions (Lee and Zeevaart 2007). The studies also indicated that the inductive photoperiod decreases GA2ox transcript content in the cotyledons, in the same way as in the region beneath the shoot apex in A. thaliana, as well as in L. temulentum (Eriksson et al. 2006; Jasinski et al. 2005; King et al. 2008).

Current genetic and molecular knowledge of GA-controlled photoperiodic flower induction derives primarily from studies of LDPs; however, to date, these aspects in SDPs remain poorly understood. The classical and model example of an obligatory SDP is Ipomoea nil (formerly Pharbitis nil), a member of the Convolvulaceae. The main location of photoperiodic stimulus perception in this species is the cotyledons. It was revealed that a single 16 h-long inductive night at $4-6$ days of seedling cultivation is necessary and sufficient for the transition from the vegetative to generative phase (King et al. 1987). Despite a number of physiological studies carried out on I. nil, the data concerning GA involvement in photoperiodic flower induction are ambiguous. Kulikowska-Gulewska et al. (2000) demonstrated that exogenous $\mathrm{GA}_{3}$ applied to the cotyledons stimulated the intensity of flowering in plants cultivated under a suboptimal photoperiod ( $14 \mathrm{~h}$ of darkness). Moreover, the application of 2-chloroethyl trimethylammonium chloride (CCC) —an inhibitor of $\mathrm{GA}_{3}$ biosynthesis - to the cotyledons during the inductive night inhibited flowering, while exogenous $\mathrm{GA}_{3}$ application reversed this effect (Kulikowska-Gulewska et al. 2000). On the other hand, Ogawa (1981) reported that flowering was stimulated by $\mathrm{GA}_{3}$ only when it was applied to the shoot apex, not to the cotyledons (Ogawa 1981). Additionally, the effectiveness of GAs could be dependent on such factors as GA structure/type, site of action, the sensitivity of the target organ or time of treatment relative to a single inductive dark period. For example, $\mathrm{GA}_{3}$ applied before the $16 \mathrm{~h}$-long night stimulates flowering but, after this period, inhibits that process (King et al. 1987). Furthermore, there are also data indicating that GAs are not essential for the flower induction process in I. nil (Takeno et al. 1996).

The aim of this work was the identification of full-length cDNAs of the InGA20ox3 and InGA2oxI genes encoding enzymes responsible for GA homeostasis. To investigate the involvement of GAs in flower induction, we studied the expression patterns of both genes and determined the tissue and cellular immunolocalisation of $\mathrm{GA}_{3}$ in the cotyledons of 5-day-old seedlings growing under inductive and noninductive photoperiodic conditions.

\section{Materials and methods}

\section{Plant material and growing conditions}

The seeds of Ipomoea nil cv. Violet (Marutane Seed Co., Kyoto, Japan) were prepared and sown as described by Wilmowicz et al. (2008). The cultivation was conducted under controlled thermal $\left(25 \pm 1{ }^{\circ} \mathrm{C}\right)$ and light (LD-8 h darkness $/ 16 \mathrm{~h}$ light, fluorescent white cold light and white light lamps of a combined power flux of 18.3 and $6 \mathrm{~W} / \mathrm{m}^{3}$, Polam, Warsaw, Poland) conditions for the first 5 days. After this time, one group of the plants were transferred to SD conditions ( $16 \mathrm{~h}$ darkness/ $8 \mathrm{~h}$ light), while the second group were left in the growth chamber under LD conditions (control). During the dark period, all procedures were carried out under green light conditions. The cotyledons without petioles were collected every $2 \mathrm{~h}$ throughout the whole diurnal cycle. The material for RNA isolation was immediately frozen in liquid nitrogen and stored at $-80^{\circ} \mathrm{C}$, while tissue fragments for microscopy experiments were processed when fresh. The experiments were repeated at least three times, and the results were presented as an arithmetic mean \pm standard error (SE).

\section{Molecular cloning of InGA20ox3 and InGA2ox1 cDNAs}

Frozen cotyledons were powdered in liquid nitrogen using mortar and pestle. Total RNA was extracted with a spin-column-based method (GeneMATRIX Universal RNA Purification Kit; EURx, Warsaw, Poland) according to the manufacturer's guidelines. DNA was removed by deoxyribonuclease I (Fermentas, St. Leon-Rot, Germany). Isolated RNA ( $1 \mu \mathrm{g})$ was reverse transcribed with a Transcriptor High Fidelity cDNA Synthesis Kit (Roche, Mannheim, Germany). Touchdown PCR $\left(96{ }^{\circ} \mathrm{C}\right.$ for $600 \mathrm{~s} ; 40$ cycles of $96{ }^{\circ} \mathrm{C}$ for $60 \mathrm{~s}$, $60-54{ }^{\circ} \mathrm{C}\left(\right.$ InGA20ox3) or $63-57^{\circ} \mathrm{C}($ InGA2oxl) for $45 \mathrm{~s}$ and $74{ }^{\circ} \mathrm{C}$ for $60 \mathrm{~s} ; 74{ }^{\circ} \mathrm{C}$ for $420 \mathrm{~s}$; cooling at $4{ }^{\circ} \mathrm{C}$ ) was performed in the T3 Thermocycler (Biometra, Göttingen, Germany) with the use of first-strand cDNA $(0.1 \mu \mathrm{g}), 1 \times$ buffer B, dNTP mix $(0.2 \mathrm{mM}), \mathrm{Mg}^{2+}(3 \mathrm{mM})$, degenerate primers $(1 \mu \mathrm{M})$ (Table S1), Perpetual Taq DNA Polymerase ${ }^{\text {HOT START }}$ (1.25 U) (EURx) and deionized $\mathrm{H}_{2} \mathrm{O}$ up to a final volume of $50 \mu$ l. The amplified cDNA fragments of InGA20ox 3 (773 bp) and InGA2oxI (665 bp) were isolated, purified from an agarose gel (GeneMATRIX Agarose Out DNA Purification Kit, EURx) and ligated into the pCRII-TOPO vector (from TOPO TA Cloning Kit; Invitrogen, Carlsbad, CA, USA). Next, the plasmids were transferred into chemically competent One Shot Mach1-T1 E. coli cells, which 
were plated onto Petri dishes containing S-Gal/LB Agar Blend (Sigma-Aldrich, St. Louis, MO,USA) and ampicillin $(50 \mu \mathrm{g} / \mathrm{mL})$ (ICN Polfa Rzeszów, Poland). White colonies were selected and cultured $\mathrm{o} / \mathrm{n}$ in liquid $2 \times \mathrm{LB}$ medium containing ampicillin. DNA plasmids were isolated (GeneMATRIX Plasmid Miniprep DNA Purification Kit, EURx) and sequenced (Genomed, Warsaw, Poland). The full-length cDNAs of the investigated genes were obtained using the 5'-3'FirstChoice RLM-RACE Kit (Ambion Inc., Austin, TX, USA), SuperTaq-Plus Polymerase (Ambion) and designed primers (Table S1). In silico data analyses were performed using BlastN, BlastP, ExPASy (Translate tool, ProtParam) and Phylogeny.fr software.

\section{Expression analysis}

cDNAs were obtained from the cotyledons of plants growing under different photoperiodic conditions in the same way as for the molecular cloning for the genes. For each gene amplification, real-time quantitative PCR (qPCR) with specific primers (Table $\mathrm{S} 1$ ) and universal probe library (UPL) hydrolysis probes (Roche) was used. The actin gene (InACT4) was selected as a reference endogenous control for normalization purposes (Glazińska et al. 2014; Marciniak et al. 2017; Wilmowicz et al. 2016b). qPCR with mixtures containing $0.1 \mu \mathrm{g}$ of cDNA, $0.2 \mu \mathrm{M}$ FP/RP, $0.05 \mu \mathrm{M}$ UPL and $1 \times$ LightCycler TaqMan Master Mix (LightCycler TaqMan Master Kit, Roche), was performed in $20 \mu \mathrm{l}$ volumes in glass capillaries using a LightCycler 2.0 system (Roche). cDNA-free negative controls were included. The reactions were carried out as follows: $96{ }^{\circ} \mathrm{C}$ for $600 \mathrm{~s} ; 45$ cycles of $96^{\circ} \mathrm{C}$ for $10 \mathrm{~s}, 58^{\circ} \mathrm{C}$ (InGA20ox 3 and InGA2oxI) and $55{ }^{\circ} \mathrm{C}\left(\right.$ InACT4) for $15 \mathrm{~s}, 72{ }^{\circ} \mathrm{C}$ for $1 \mathrm{~s} ; 40{ }^{\circ} \mathrm{C}$ for $30 \mathrm{~s}$. Relative expression was calculated using the standard curves from serial dilutions of cDNAs for both the studied and reference genes. The final values were determined by an automated method (Light Cycler Software 4.0, Roche), which is recommended for all applications. Three independent replications for each cDNA were performed. Statistical analyses and graphical presentation were made by Sigma Plot 2001 .

\section{Immunolocalisation of $\mathbf{G A}_{3}$}

Cotyledons harvested from 5-day-old I. nil seedlings were fixed in phosphate-buffered saline buffer $(1 \times \mathrm{PBS}, \mathrm{pH} 7.2)$ containing $4 \%$ paraformaldehyde (w/v), $0.2 \%$ glutaraldehyde (v/v) and 3\% EDAC [N-ethyl-N'-(3-dimethylaminopropyl) carbodiimide hydrochloride] (w/v) (Sigma-Aldrich) for $12 \mathrm{~h}$ at $4{ }^{\circ} \mathrm{C}$ (Lofke et al. 2013). Then, the samples were dehydrated, supersaturated and embedded in BMM resin (butyl methacrylate, methyl methacrylate, $0.5 \%$ (w/v) benzoin ethyl ether, $10 \mathrm{mM}$ dithiothreitol; Fluka, Buchs, Switzerland) as Wilmowicz et al. (2016a) previously described. Semi-thin sections $(1.5 \mu \mathrm{m})$ were cut on an Ultracut microtome (Reichert-Jung, Germany) and then placed on glass slides covered with Biobond (BBInternational, UK).

The sections were then incubated o/n at $4{ }^{\circ} \mathrm{C}$ with the primary antibody (anti-GA ${ }_{3}$ ) (Agrisera, Vännäs, Sweden) diluted 1:50 in 1\% bovine serum albumin (BSA) in $1 \times \mathrm{PBS}$ (pH 7.2). Next, a DyLight Alexa 488 conjugated IgG diluted 1:250 in PBS buffer for $2 \mathrm{~h}$ at $37^{\circ} \mathrm{C}$ served as the secondary antibody. A control reaction (Fig. S4) was carried out by omitting the incubation with primary antibody. The samples were observed in a Leica DMI4000B inverted microscope using the filters: BP365, FT395, and LP397.

\section{Results and discussion}

Despite the presence of many common genes encoding proteins involved in flowering pathways among LDPs and SDPs, the regulation of their expression by various factors is different (Hayama et al. 2007). This variability is most likely because the evolutionary appearance of these plants was not concurrent but was the effect of the gradual adaptation to environmental conditions (Hayama et al. 2003). Therefore, studies of flowering induction in different species seem to be meaningful. Moreover, little is known about the involvement of GAs in the photoperiod response. Knowledge concerning the molecular pathways of GA metabolism or their tissue and cellular localisation under different photoperiodic conditions is crucial to comprehensively understanding the fundamental mechanisms of plant sexual reproduction. Furthermore, the genetic manipulation of GA level, which often involves 2ODD-catalysed steps, can be useful for horticultural purposes (Lester et al. 2005).

In this paper, the complete cDNA sequences of InGA20ox3 (HM017849) and InGA2oxl (GU189414) (Fig. S1d, S2d) were isolated by using degenerate primers (Fig. S1a, S2a) and 5'-3' RACE-PCR (Fig. S1b, c; S2b, c). The presence of all conserved domains and characteristic amino acids in the predicted InGA20ox3 and InGA2ox1 (Fig. S1d, S2d) suggests that these genes encode functional proteins. The sequences exhibit the highest similarity to NtGA20ox1 from Nicotiana tabacum (89\%) and NoGA2ox2 from Nerium oleander (88\%) (Fig. S3).

In the cotyledons of $I$. nil, photoperiod significantly affects the accumulation of InGA20ox3 and InGA2oxI transcripts, which occurred only in the second half of the inductive night (8-16 h) (Fig. 1). Furthermore, the expression level of the gene encoding the enzyme responsible for GA deactivation was generally much higher than that related to GA biosynthesis (Fig. 1a, b). This difference may be related to the diverse kinetics of the reactions catalysed by both 2ODDs (Lester et al. 2005). We noticed that exposure of plants grown under non-inductive 


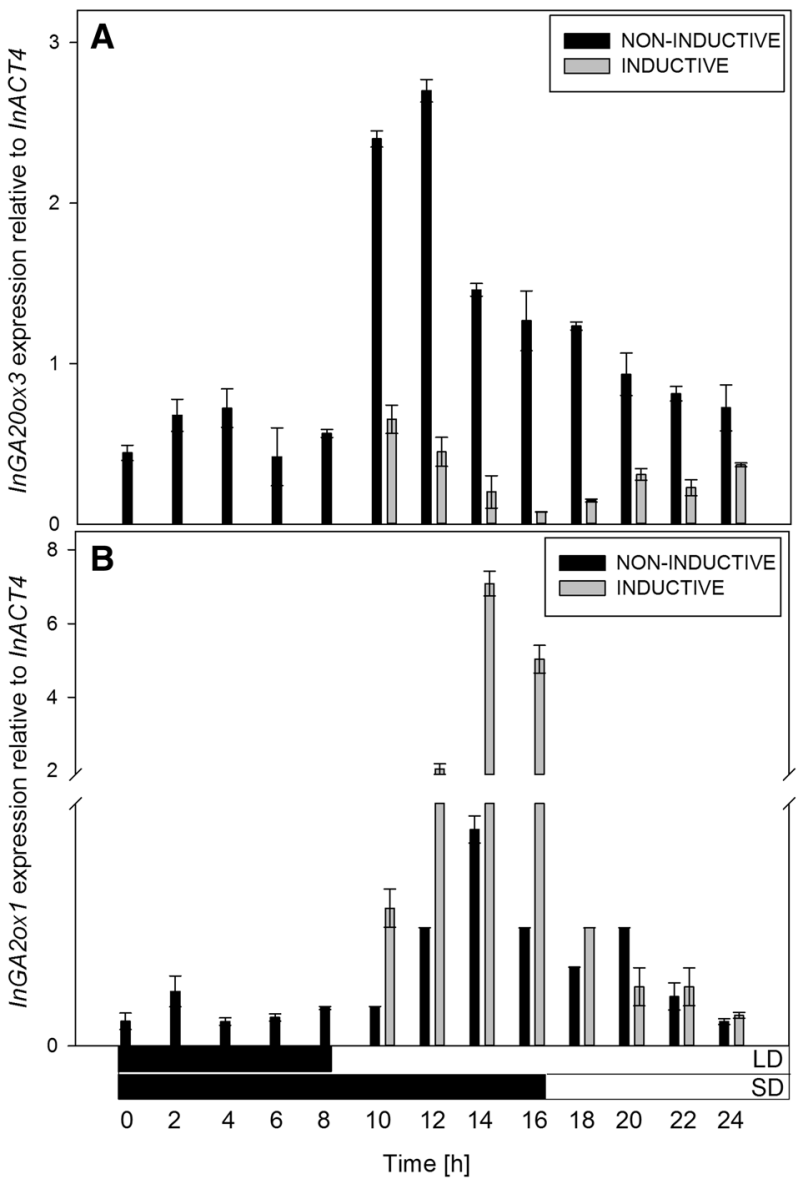

Fig. 1 The expression of the InGA20ox3 (a) and InGA2oxl (b) genes relative to InACT4 in the cotyledons of 5-day-old Ipomoea nil seedlings growing under various photoperiodic conditions. The horizontal, black lines under the "Time" axis demonstrate the duration of the dark period. $S D$ short day ( $8 \mathrm{~h}$ light/16 h darkness), $L D$ long day (16 h light/ $8 \mathrm{~h}$ darkness). All data are the results of three biological and three technical replications $(n=9)$ and are shown as the mean \pm standard error

LD conditions to light $(8 \mathrm{~h})$ causes a sudden increase in InGA20ox3 transcripts (Fig. 1a). In the case of plants grown under inductive SD conditions, a rapid decrease in mRNA content was observed in the second half of the inductive night $(8-16 \mathrm{~h})$. Additionally, $16 \mathrm{~h}$ of darkness substantially elevated the expression of the InGA2oxI gene, with the maximum value at $14 \mathrm{~h}$ (Fig. 1b). Interestingly, exposing the plants to light after a $16 \mathrm{~h}$-long night rapidly reduces InGA2oxl mRNA content by approximately $10 \times$ already at $18 \mathrm{~h}$. Physiological studies indicate that the period between 8 and $16 \mathrm{~h}$ of darkness is the most essential for flowering in $I$. nil. The maximal sensitivity to night break usually occurred at $\sim 8 \mathrm{~h}$ of the inductive night (Vince-Prue and Gressel 1985). Disruption of the dark period by exposure to red light for 5 min prevents flowering (Takimoto and Hamner 1965). On the basis of the results presented here, we concluded that the InGA20ox3 and InGA2oxI genes are strongly photoperiod-regulated.

In order to understand whether there was a correlation between the transcriptional activity of the investigated genes and the level of active $\mathrm{GA}_{3}$ we performed immuno-

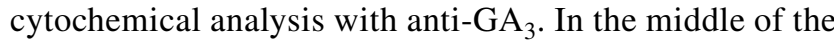
inductive night $(8 \mathrm{~h})$, moderate $\mathrm{GA}_{3}$ accumulation in the cotyledons of $I$. nil seedlings was observed (Fig. 2a-d). In turn, at the end of the $16 \mathrm{~h}$-long dark period (SD $16 \mathrm{~h}$, Fig. 2i, j), the phytohormone molecules were almost undetectable, and green fluorescence was limited to the vascular tissue of the cotyledons (Fig. 2k, 1). Conversely, the highest level of $\mathrm{GA}_{3}$ was detected in the cotyledons of seedlings cultivated under non-inductive conditions (LD $16 \mathrm{~h}$ ), especially near the vascular bundle (Fig. 2e, f). At the cellular level, we then observed dispersed signal indicating the presence of $\mathrm{GA}_{3}$ in particular whole cells of the xylem and phloem and in the thin layer of cytoplasm of spongy mesophyll cells (Fig. $2 \mathrm{~g}, \mathrm{~h}$ ). We also found that the cotyledonary bodies were not labelled (Fig. 2e, f). From the literature, it is known that these semi-transparent structures with the surrounding cells of the mesophyll are potential locations of flower inductor synthesis (Tretyn et al. 1996). The lignified cell walls of the xylem and the cuticle were labelled (Fig. 2a, c, e, g, i, k) but appeared white-blue because of autofluorescence under ultraviolet light (DAPI staining, Fig. 2b, d, f, h, j, l).

Thus, our results concerning the transcriptional activity of InGA20ox3 and InGA2oxI (Fig. 1) are compatible with the accumulation of $\mathrm{GA}_{3}$ (Fig. 2). The relationship between the expression of GA metabolism genes and phytohormone content was also observed in the leaves of $L$. temulentum. Because this species has a different photoperiod sensitivity from $I$. nil, the inductive photoperiod enhanced LtGA20ox expression and simultaneously the level of $\mathrm{GA}_{5}$ (King et al. 2006). Additionally, KulikowskaGulewska et al. (2000) showed that endogenous content of GAs in the cotyledons of I. nil decreased during the second half of the inductive night (Kulikowska-Gulewska et al. 2000), which is in line with our findings presented here. Based on the presence of strong labelling in the phloem and xylem cells (Fig. 2d, h, 1), it is tempting to speculate that GAs are translocated within vascular bundles. Several studies support the thesis of local and long-distance transport of these phytohormones; however, due to the presence of many forms of GA and the possibility of their conversion, it is still unknown which form is a mobile molecule. Previous experiments performed on phloem exudates also revealed the presence of $\mathrm{GA}_{12}$ in xylem and phloem, which suggest its translocation (Regnault et al. 2016). GA transport occurs in the whole system of vascular tissue as a result of an intensive exchange between the phloem and xylem. 
Fig. 2 Localisation of $\mathrm{GA}_{3}$ in the cotyledons of 5-day-old $I$. nil seedlings growing in darkness for $8 \mathrm{~h}(\mathbf{a}-\mathbf{d}$; the common time variant for $\mathrm{LD}$ and $\mathrm{SD}$ conditions), and under LD (e--h) and SD (i-l) conditions in $16 \mathrm{~h}$. Nuclei were stained with DAPI $(\mathbf{b}, \mathbf{d}, \mathbf{f}, \mathbf{h}, \mathbf{j}, \mathbf{l})$. Yellow and orange staining show the autofluorescence of the cell walls, and green staining indicates $\mathrm{GA}_{3}$ localisation. In plants cultivated under continuous darkness $(0-8 \mathrm{~h})$, the presence of $\mathrm{GA}_{3}$ in the phloem and xylem cells, as well as in the cytoplasm of the spongy mesophyll (a-d) was detected. Much stronger fluorescence in the same cells of cotyledons harvested in LD conditions was observed $(0-8 \mathrm{~h}$ darkness + 8-16 h light) (e-h). The signal was almost undetectable in the examined tissue dissected from cotyledons after $16 \mathrm{~h}$ of darkness (SD) (i-l). The red arrows indicate the presence of green fluorescence. Enlarged images of vascular tissue (white boxes in $\mathbf{a}, \mathbf{b}, \mathbf{e}, \mathbf{f}$, $\mathbf{i}, \mathbf{j})$ are presented in $\mathbf{c}, \mathbf{d}, \mathbf{g}, \mathbf{h}$, k, l. Symbols are as follows: $C B$ cotyledonary body, $P M$ palisade mesophyll, $S M$ spongy mesophyll, $U E$ upper epidermis, $L E$ lower epidermis, $V B$ vascular bundle, $X$ xylem, $P$ phloem, $N$ nucleus. Bars $50 \mu \mathrm{m}$. (Color figure online)
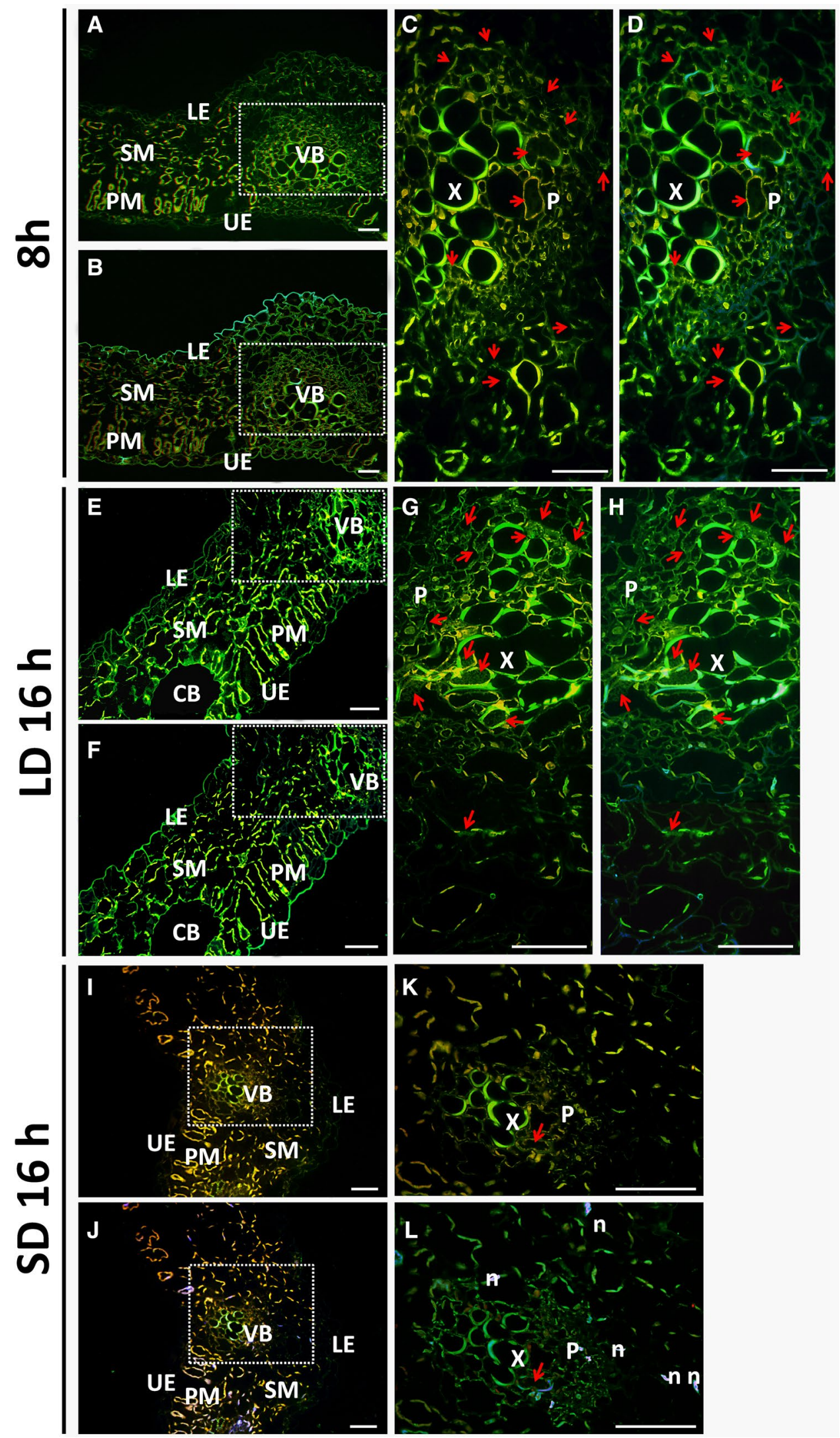


\section{Conclusion}

Our results show that low content of $\mathrm{GA}_{3}$ in the second half of the inductive night, resulting from a proper balance between expression of the InGA20ox3 and InGA2oxI genes, is an essential part of the photoperiodic flower induction mechanism in the SDP I. nil.

Acknowledgements This work was supported by the National Science Centre [Grant No N303 811240] and the project entitled "Scholarships for doctoral 2008/2009-ZPORR” [SPS. IV-3040-UE/619/2009].

Open Access This article is distributed under the terms of the Creative Commons Attribution 4.0 International License (http://creativecommons.org/licenses/by/4.0/), which permits unrestricted use, distribution, and reproduction in any medium, provided you give appropriate credit to the original author(s) and the source, provide a link to the Creative Commons license, and indicate if changes were made.

\section{References}

Eriksson S, Bohlenius H, Moritz T, Nilsson O (2006) $\mathrm{GA}_{4}$ is the active gibberellin in the regulation of Leafy transcription and Arabidopsis floral initiation. Plant Cell 18:2172-2181. https:// doi.org/10.1105/tpc.106.042317

Glazińska P, Wojciechowski W, Wilmowicz E, Zienkiewicz A, Frankowski K, Kopcewicz J (2014) The involvement of InMIR167 in the regulation of expression of its target gene InARF8, and their participation in the vegetative and generative development of Ipomoea nil plants. J Plant Physiol 171:225-234. https://doi. org/10.1016/j.jplph.2013.07.011

Hayama R, Yokoi S, Tamaki S, Yano M, Shimamoto K (2003) Adaptation of photoperiodic control pathways produces short-day flowering in rice. Nature 422:719-722. https://doi.org/10.1038/ nature 01549

Hayama R, Agashe B, Luley E, King R, Coupland G (2007) A circadian rhythm set by dusk determines the expression of FT homologs and the short-day photoperiodic flowering response in Pharbitis. Plant Cell 19:2988-3000. https://doi.org/10.1105/tpc.107.052480

Hisamatsu T, King RW, Helliwell CA, Koshioka M (2005) The involvement of gibberellin 20-oxidase genes in phytochrome-regulated petiole elongation of Arabidopsis. Plant Physiol 138:1106-1116. doi: https://doi.org/10.1104/pp.104.059055

Jasinski S, Piazza P, Craft J, Hay A, Woolley L, Rieu I, Phillips A, Hedden P, Tsiantis M (2005) KNOX action in Arabidopsis is mediated by coordinate regulation of cytokinin and gibberellin activities. Curr Biol 15:1560-1565. https://doi.org/10.1016/j. cub.2005.07.023

King RW, Pharis RP, Mander LN (1987) Gibberellins in relation to growth and flowering in Pharbitis nil Chois. Plant Physiol 84:1126-1131. https://doi.org/10.1104/pp.84.4.1126

King RW, Moritz T, Evans LT, Martin J, Andersen CH, Blundell C, Kardailsky I, Chandler PM (2006) Regulation of flowering in the long-day grass Lolium temulentum by gibberellins and the FLOWERING LOCUS T gene. Plant Physiol 141:498-507. https://doi. org/10.1104/pp.106.076760

King RW, Mander LN, Asp T, MacMillan CP, Blundell CA, Evans LT (2008) Selective deactivation of gibberellins below the shoot apex is critical to flowering but not to stem elongation of Lolium. Mol Plant 1:295-307. https://doi.org/10.1093/mp/ssm030

Kulikowska-Gulewska H, Majewska M, Kopcewicz J (2000) Gibberellins in the control of photoperiodic flower transition in Pharbitis nil. Physiol Plant 108:202-207. https:// doi.org/10.1034/j.1399-3054.2000.108002202.x

Lee DJ, Zeevaart JAD (2007) Regulation of gibberellin 20-oxidase 1 expression in spinach by photoperiod. Planta 226:35. https://doi. org/10.1007/s00425-006-0463-1

Lester DR, Phillips A, Hedden P, Andersson I (2005) Purification and kinetic studies of recombinant gibberellin dioxygenases. BMC Plant Biol 5:19. https://doi.org/10.1186/1471-2229-5-19

Lofke C, Zwiewka M, Heilmann I, Van Montagu MCE, Teichmann T, Friml J (2013) Asymmetric gibberellin signaling regulates vacuolar trafficking of PIN auxin transporters during root gravitropism. PNAS 110:3627-3632. https://doi.org/10.1073/pnas.1300107110

Marciniak K, Wilmowicz E, Kućko A, Kopcewicz J (2017) Photoperiod and ethylene-dependent expression of gibberellin biosynthesis gene InEKOI during flower induction of Ipomoea nil. Biol Plant. https://doi.org/10.1007/s10535-017-0743-6

Mutasa-Gottgens E, Hedden P (2009) Gibberellin as a factor in floral regulatory networks. J Exp Bot 60:1979-1989. https://doi. org/10.1093/jxb/erp040

Ogawa Y (1981) Stimulation of the flowering of Pharbitis nil Chois. by gibberellin $\mathrm{A}_{3}$ : time dependent action at the apex. Plant Cell Physiol 4:675-681. https://doi.org/10.1093/oxfordjournals.pcp. a076211

Olszewski N, Sun TP, Gubler F (2002) Gibberellin signaling: biosynthesis, catabolism, and response pathways. Plant Cell 14:61-80. https://doi.org/10.1105/tpc.010476

Regnault T, Daviere J-M, Achard P (2016) Long-distance transport of endogenous gibberellins in Arabidopsis. Plant Signal Behav 11:e1110661-1-3. https://doi.org/10.1080/15592324.2015.1110 661

Rieu I, Ruiz-Rivero O, Fernandez-Garcia N, Griffiths J, Powers SJ, Gong F, Linhartova T, Eriksson S, Nilsson O, Thomas SG, Phillips AL, Hedden P (2008) The gibberellin biosynthetic genes AtGA20ox1 and AtGA20ox2 act, partially redundantly, to promote growth and development throughout the Arabidopsis life cycle. Plant J 53:488-504. https://doi. org/10.1111/j.1365-313X.2007.03356.x

Takeno K, Tsuruta T, Maeda T (1996) Gibberellins are not essential for photoperiodic flower induction of Pharbitis nil. Physiol Plant 97:397-401. https://doi.org/10.1034/j.1399-3054.1996.970226.x

Takimoto A, Hamner KC (1965) Studies on red light interruption in relation to timing mechanisms involved in the photoperiodic response of Pharbitis nil. Plant Physiol 40:852-854. https://doi. org/10.1104/pp.40.5.852

Tretyn A, Kendrick RE, Fujioka S, Sakurai A (1996) Cytochemical and histochemical characterization of cotyledonary bodies from Pharbitis nil seedlings. Protoplasma 19:205-214. https://doi. org/10.1007/BF01281818

Vince-Prue D, Gressel J (1985) Pharbitis nil. In: Halevy AH (ed) Handbook of flowering, vol IV. CRC Press, Boca Raton, pp 47-81

Wilmowicz E, Kęsy J, Kopcewicz J (2008) Ethylene and ABA interactions in the regulation of flower induction in Pharbitis nil. J Plant Physiol 165:1917-1928. https://doi.org/10.1016/j. jplph.2008.04.009

Wilmowicz E, Frankowski K, Kućko A, Świdziński M, de Dios Alchéd J, Nowakowska A, Kopcewicz J (2016a) The influence of abscisic acid on the ethylene biosynthesis pathway in the functioning of the flower abscission zone in Lupinus luteus. J Plant Physiol 206:49-58. https://doi.org/10.1016/j.jplph.2016.08.018

Wilmowicz E, Kućko A, Frankowski K, Świdziński M, Marciniak K, Kopcewicz J (2016b) Methyl jasmonate-dependent senescence of cotyledons in Ipomoea nil. Acta Physiol Plant 38:222. https://doi. org/10.1007/s11738-016-2244-1

Zeevaart JAD (1983) Gibberellins and flowering. In: Crozier A (ed) The biochemistry and physiology of gibberellins, vol 2. Praeger Publishers, New York, pp 333-374 